\title{
Bronchoalveolar lavage during neutropenic episodes: diagnostic yield and cellular pattern
}

\author{
C. Cordonnier*, E. Escudier**, F. Verra+, L. Brochard+, \\ J.F. Bernaudin**, J. Fleury-Feith**
}

Bronchoalveolar lavage during neutropenic episodes: diagnostic yield and cellular pattern. C. Cordonnier, E. Escudier, F. Verra, L. Brochard, J.F. Bernaudin, J. Fleury-Feith. CERS Journals Ltd 1994.

ABSTRACT: Few data are available concerning the relationship between alveolar and blood cell populations during neutropenia. We wanted to compare the value of pulmonary endoscopic procedures with lavage in neutropenic (polymorphonuclear $(P M N)$ count $\left.\leq 1,000 \cdot \mathrm{mm}^{-3}\right)$ and non-neutropenic settings.

We therefore, retrospectively, reviewed the results of 118 investigations for pneumonia in patients with malignant haematological diseases. All had bronchoalveolar lavage (BAL), and some had additional studies with protected bacteriological samples. Each BAL specimen was studied after cytocentrifugation by cytological examination for opportunistic infections, haemorrhage, virus, legionellae, and bacteriological cultures.

The diagnostic yield of all endoscopic procedures (BAL, telescoping plugged catheter and protected specimen brush) was $53 \%$ in neutropenic (Group 1) and $61 \%$ in nonneutropenic (Group 2) patients. The aetiological pattern of pneumonia was nearly the same in the two groups, except for more alveolar proteinosis in Group 1 and more cytomegalovirus (CMV) in Group 2. The absolute number of alveolar cells recovered through BAL (total number, macrophages, lymphocytes and PMNs) was significantly lower in neutropenic patients.

We conclude that: 1) neutropenic patients with pneumonia require the same investigative approach as non-neutropenic patients; 2) profound neutropenia may be concomitant with a decreased cellularity of alveoli, which may reflect the consequences of marrow aplasia on the pulmonary cell population and/or direct effect of chemotherapy on the lung.

Eur Respir J., 1994, 7, 114-120.

The diagnostic yield of endoscopic procedures, especially bronchoalveolar lavage (BAL), is well-established in immunocompromised hosts with pneumonia [1]. In such patients, BAL may provide the diagnosis of pneumonia in 50-70\% of cases, with differences in yield varying with the type of pneumonia and the patient population [2-5]. Moreover, BAL is uniformly accepted as a safe procedure, and has reduced the necessity for the routine use of open lung biopsy. There has been little published on whether differences can be expected when BAL is performed in neutropenic patients, compared to nonneutropenic ones [6-8]. However, more bacterial and fungal pneumonias are expected in severely neutropenic patients, and most patients receive broad-spectrum antibiotics and often antifungal agents early, which may influence the diagnostic yield of samples at endoscopy. In addition, apart from some studies of patients after bone marrow transplantation and several experimental animal models [9-13], few data are available on the relationship between the different alveolar and blood cell populations during neutropenia.

To evaluate the usefulness of the endoscopic procedures with BAL in the neutropenic setting, we reviewed
*Unit of Bone Marrow Transplantation, **Unit of Cytology and LHPD, and +Medical Intensive Care Unit, Hôpital Henri Mondor, Creteil, France.

Correspondence: C. Cordonnier Service d'Hématologie Clinique Hôpital Henri Mondor 94010 Créteil

France

Keywords: Bronchoalveolar lavage Neutropenia

opportunistic infection

pneumonia in immunocompromised patients

Received: February 31993

Accepted after revision June 231993
57 episodes of pneumonia occurring in neutropenic patients during a 3 yr period, which were investigated with fibreoptic bronchoscopy and BAL. We compared this group with a group of non-neutropenic patients, evaluated in the same way during the same period in our haematology department. This comparison was carried out to determine the diagnostic yield of BAL and other endoscopic procedures, and their safety and therapeutic implications. Moreover, in order to determine whether neutropenia was associated with poor alveolar cellularity, the groups were compared with regard to the concentration of alveolar cells recovered by BAL.

\section{Patients}

We retrospectively studied the specimens from 118 BALs, performed via fibreoptic bronchoscopy in 107 patients with haematological diseases, for 113 episodes of pneumonia over a 29 month period. Fifty seven episodes occurred during neutropenia, defined as a polymorphonuclear (PMN) count $<1,000 \cdot \mathrm{mm}^{-3}$ (Group 1). Fifty six episodes occurring in non-neutropenic patients composed Group 2. Mean age, sex, underlying diseases and mean PMN blood count of these patients are shown in 
Table 1. - Main clinical characteristics of the patients from Group 1 (PMN $<1,000$ cells $\cdot \mathrm{mm}^{-3}$ ) and group 2 (PMN $>1,000$ cells $\cdot \mathrm{mm}^{-3}$ )

\begin{tabular}{|c|c|c|c|}
\hline & Group 1 & Group 2 & Total \\
\hline Patients & 56 & 51 & 107 \\
\hline Episodes of pneumonia & 57 & 56 & 113 \\
\hline Bronchoscopy with BAL & 60 & 58 & 118 \\
\hline \multicolumn{4}{|l|}{ Age yrs } \\
\hline $\begin{array}{l}\text { mean } \pm \text { SD } \\
\text { (range) }\end{array}$ & $\begin{array}{c}42 \pm 16 \\
(15-77)\end{array}$ & $\begin{array}{c}39 \pm 16 \\
(14-76)\end{array}$ & $40 \pm 16$ \\
\hline Males/females & $37 / 19$ & $36 / 15$ & $73 / 34$ \\
\hline \multicolumn{4}{|l|}{ PMN blood count cells $\cdot \mathrm{mm}^{-3}$} \\
\hline mean \pm SD & $225 \pm 290$ & $3990 \pm 2330$ & \\
\hline (range) & $0-999$ & $1000-10500$ & \\
\hline \multicolumn{4}{|l|}{ Underlying disease } \\
\hline AML or blastic phase CML & 24 & 12 & 36 \\
\hline ALL & 6 & 10 & 16 \\
\hline CML & 4 & 9 & 13 \\
\hline \multicolumn{4}{|l|}{ Aplastic anaemia or } \\
\hline myelodysplastic sydrome & 6 & 3 & 9 \\
\hline Lymphoma & 10 & 11 & 21 \\
\hline CLL or myeloma & 6 & 5 & 11 \\
\hline ITP & 0 & 1 & 1 \\
\hline \multicolumn{4}{|l|}{ Therapies } \\
\hline Autologous BMT & 2 & 1 & 3 \\
\hline Allogenic BMT & 14 & 28 & 42 \\
\hline Chemotherapy & 27 & 19 & 46 \\
\hline \multicolumn{4}{|l|}{ Chest radiographic pattern } \\
\hline Focal & 31 & 24 & 55 \\
\hline Multifocal or diffuse & 26 & 32 & 58 \\
\hline
\end{tabular}

PMNs: polymorphonuclear; AML: acute myeloid leukaemia; ALL: acute lymphoid leukaemia; CML: chronic myeloid leukaemia; CLL: chronic lymphocytic leukaemia: ITP: idiopathic thrombocytopenic purpura; BMT: bone marrow transplantation.

Table 1. Three patients in each group underwent BAL for each of two different episodes of pneumonia. Five patients (three in Group 1, two in Group 2) had two procedures during the same episode. In Group 1, 35 episodes occurred in patients having PMN counts $<500$ cells $\cdot \mathrm{mm}^{-3}$ at the time of the procedure (Group 1A), and 21 in patients with PMN counts between 500-1,000 cells $\cdot \mathrm{mm}^{-3}$ (Group 1B). In Group 2, eight BALs were performed in patients who had recovered PMN counts $\geq 1,000$ cells $\cdot \mathrm{mm}^{-3}$ for less than 15 days. The mean $( \pm \mathrm{SD})$ and median durations of neutropenia at the time of fibreoptic bronchoscopy in Group 1 were $90 \pm 35$ days and 32 days, respectively. This long duration of neutropenia was explained by the presence, in Group 1, of patients with chronic lymphoid disorders, such as chronic lymphocytic leukaemia (CLL), who were neutropenic for several months when pneumonia occurred. None of the patients in the study had received growth factors.

\section{Methods}

\section{Procedures}

Since 1980, fibreoptic bronchoscopy with BAL has become a routine diagnostic procedure for new pulmonary infiltrates occurring in immunocompromised hosts in our institution; including patients who have undergone bone marrow transplantation [14]. Most episodes of pneumonia at our hospital were investigated with this procedure if the patient consented, had an arterial oxygen tension $\left(\mathrm{PaO}_{2}\right) \geq 60 \mathrm{mmHg}(8 \mathrm{kPa})$ with or without administration of oxygen, and if it was considered that there could be a therapeutic benefit from the information gained from the procedure. Other usual investigations, such as blood cultures, serological tests for cytomegalovirus (CMV), toxoplasmosis, and legionellosis were routinely performed, as indicated by the clinical course. As far as possible, the bronchoscopy was performed before starting antibiotics, except during the weekend, or when concomitant fever and neutropenia required an early antibiotic therapy. Eighty one of $118(68 \%)$ BALs were performed in patients on antibiotics, more frequently in the neutropenic (91\%) than non-neutropenic $(47 \%)$ patients. The time of treatment prior to endoscopy was similar in the two groups (18.6 vs 16.7 days). Most of these patients were receiving antibiotics for other reasons than pneumonia at the time of bronchoscopy, especially in the neutropenic group. In only 4 out of $57(7 \%)$ cases in Group 1 and 7 out of $56(13 \%)$ cases in Group 2, were the patients receiving antibiotics for pneumonia when bronchoscopy was performed. The delay between the first signs of pneumonia and endoscopy never exceeded 8 days. The radiographic pattern of pneumonia is shown in table 1; approximately half were focal, half diffuse.

Fibreoptic bronchoscopy was performed as described previously [14], with a Pentax FB $19 \mathrm{H}$ fibreoptic bronchoscope. Each lavage consisted of a slow infusion of three $50 \mathrm{ml}$ aliquots of sterile $0.9 \%$ saline solution, and sequential instillation and aspiration. A sample of fluid was reserved for bacteriological, viral and fungal cultures. Legionella pneumophila was sought on bronchial aspiration and/or on BAL fluid, by direct immunofluorescence and cultures on buffer charcoal yeast extract (BCYE) medium. Apart from cytological examination, the presence of CMV in BAL fluid was determined by an indirect technique described previously [15], using an 
antibody directed against a late antigen. Specific antibodies were also used to look for other viruses (Herpes simplex and Varicella zoster virus, respiratory syncitial virus, adenovirus, and parainfluenza virus type 3 ). The main part of the fluid was pooled and used for cytological examination [14]. A total cell count was performed, as well as a differential cell count, on cytocentrifuge preparations (Cytospin II, Shandon Southern Instruments, Sewickley, PA, USA) using the May-Grünwald Giemsa stain. Smears obtained after centrifugation $(500 \times \mathrm{g}$ for $10 \mathrm{~min}$ ) and cytocentrifuge preparations were stained by the May-Grünwald Giemsa, Papanicolaou, Perls and Gomori-Grocott methods and examined for cytological evidence of viral, fungal and parasitic infections, and for the detection of siderophages. When a diagnosis of pulmonary alveolar proteinosis was suspected during the initial examination of the fluid, periodic acid-Schiff (PAS) staining was performed in order to detect the lipoproteinaceous material characteristic of the disease. Some of these patients were studied by electron microscopy. At least eight slides were examined for each lavage.

Because of the results of a prospective study in another department of our institution [16], we progressively extended the indications for a bronchial bacteriological sample through telescoping plugged catheter (TPC) or protected specimen brush (PSB), when a bacterial pneumonia was clinically suspected. Therefore, lavage was performed in 50 cases concomitantly with TPC (Combicath 5828-20, Plastimed Lab, Saint Leu La Forêt, France) $(n=32)$, PSB (Meditec, Watertown, USA) $(n=14)$, or both $(n=4)$, which were processed with quantitative cultures [16].

\section{Diagnostic criteria on endoscopic specimen}

The following criteria were used to establish the aetiological diagnosis of pneumonia:

1. Bacterial pneumonia: colony count $\geq 10^{3}$ colony forming-units (cfu) $\cdot \mathrm{ml}^{-1}$ on PSB or TPC specimens [16].

2. Candida or Torulopsis pneumonia: colony count $\geq 10^{3}$ $\mathrm{cfu} \cdot \mathrm{ml}^{-1}$ on PSB or TPC specimens. The finding of Candida or Torulopsis in fungal culture of BAL fluid was not considered adequate evidence to establish a causal relationship between these strains and the pneumonia.

3. Aspergillosis: identification of characteristic hyphae on microscopic examination and/or fungal culture of aspiration and/or BAL fluid, associated with epidemiological, clinical and radiological patterns consistent with this diagnosis.

4. CMV pneumonia: presence of large cells containing typical haloed "owl-eyed" basophilic intranuclear inclusions, associated with smaller intracytoplasmic inclusions and/or positive immunofluorescence for the virus in BAL specimens. According to the conclusions of a previous study [15], the positivity of virological culture of BAL fluid alone was not considered sufficient to establish the diagnosis of CMV pneumonitis.

5. Alveolar haemorrhage: presence of $\geq 20 \%$ siderophages among the total alveolar macrophage population and/or recovery of alveolar fluid which became progressively bloodier with each instilled aliquot during a non-traumatic bronchoscopy [14, 17].
6. Pulmonary alveolar proteinosis: abundant extracellular lipoproteinaceous material, PAS or Sudan black staining, associated with the characteristic electron microscopic evidence of alveolar proteinosis (accumulation of myelinic and tubular myelinic structure).

7. Hypersensitivity pneumonia: consistent clinical and radiological setting, marked hypercellularity with lymphocytosis and eosinophilia in BAL fluid, absence of other cause identified through bronchoscopy or other procdure, reversibility of the clinical, radiological and alveolar abnormalities detected by BAL after the discontinuation of the suspect drug, without addition of any other therapy.

8. False negative BAL: when a diagnosis was not made on BAL but was later demonstrated by another technique, such as second BAL, specific serology, postmortem lung biopsy or autopsy.

A diagnosis was considered to be established by cytological examination of BAL when it was made after direct observation of a pathogen or a cytopathic effect and did not require any other technique, such as culture or immunofluorescence.

Among the 26 patients who died with or from their pneumonia, postmortem lung biopsy or autopsy was performed in nine.

\section{Statistical analysis}

The frequency of various occurrences were compared using chi-squared analysis with Yate's correction for small numbers $(<30)$. Results in the differential count in different groups of patients were compared using the Student's t-test. A p value of $<0.05$ was considered significant.

\section{Results}

\section{Diagnostic yield of BAL and other endoscopic procedures}

The overall diagnostic yield of endoscopy with BAL was 64 out of $113(57 \%)$, without significant difference between Group 1 (53\%) and Group 2 (61\%) (table 2). This yield was significantly better in pneumonias with multifocal or diffuse radiological patterns $(69 \%)$, rather than in focal patterns $(47 \%)(\mathrm{p}<0.02)$. We were interested in analysing the diagnoses provided through cytology alone, as such results are usually available more quickly. The overall diagnostic yield of cytological examination of lavage fluid was 43 out of $113(38 \%)$ for all episodes, and was not significantly different in Group 1 (33\%) or in Group 2 (43\%). The various causes of pneumonia were found equally in both groups, except for alveolar proteinosis which was more frequent in Group 1, and CMV which was more frequent in Group 2 (table 2). All the cases of CMV pneumonia occurred in allogeneic transplant patients. The frequency of aspergillosis was similar in the groups, but all the cases in Group 2 were diagnosed in patients just recovering from aplasia, so that the fungus was almost always temporally related to neutropenia. Among 13 cases of aspergillosis, seven ( 2 out of 6 in Group 1 and 5 out of 7 in Group 2) were diagnosed by cytological examination of BAL and positive cultures, and six were diagnosed by culture only. 
Table 2. - Total diagnostic yield of fibreoptic bronchoscopy with BAL in 113 episodes of pneumonia

\begin{tabular}{|c|c|c|c|}
\hline Diagnosis & $\begin{array}{c}\text { Group } \\
n=57\end{array}$ & $\begin{array}{c}\text { Group } 2 \\
n=56\end{array}$ & $\begin{array}{r}\text { Total } \\
n=113\end{array}$ \\
\hline \multicolumn{4}{|l|}{ CMV } \\
\hline Alone & 1 & 7 & 11 \\
\hline+ Pneumocystis carinii & 1 & 0 & \\
\hline+ Bacteria & 0 & 1 & \\
\hline +Alveolar haemorrhage & 1 & 0 & \\
\hline Aspergillosis & & & 13 \\
\hline Alone & 4 & 5 & \\
\hline+ Bacteria & 0 & 2 & \\
\hline +Alveolar haemorrhage & 2 & 0 & \\
\hline Alveolar haemorrhage alone & 4 & 3 & 7 \\
\hline Pneumocytis carinii alone & 3 & 2 & 5 \\
\hline Viral non-CMV pneumonia & 1 & 1 & 2 \\
\hline Bacterial pneumonia alone & & & 15 \\
\hline Pseudomonas aeruginosa & 1 & 1 & \\
\hline Streptococcus sp. & 4 & 0 & \\
\hline Staphlyococcus aureus & 0 & 2 & \\
\hline Branhamella catarrhalis & 0 & 1 & \\
\hline Haemophilus influenzae (Hi) & 0 & 4 & \\
\hline $\mathrm{Hi}+$ Klebsiella pneumonia & 0 & 1 & \\
\hline Legionella pneumophila & 1 & 0 & \\
\hline Candida or Torulopsis & 2 & 0 & 2 \\
\hline Alveolar proteinosis & & & 7 \\
\hline Alone & 3 & 1 & \\
\hline+ Bacteria & 1 & 1 & \\
\hline +Alveolar haemorrhage & 1 & 0 & \\
\hline Hypersensitivity pneumonia & 0 & 2 & 2 \\
\hline Total diagnostic yield & $\begin{array}{c}30 \\
(53 \%)\end{array}$ & $\begin{array}{c}34 \\
(61 \%)\end{array}$ & $\begin{array}{c}64 \\
(57 \%)\end{array}$ \\
\hline
\end{tabular}

BAL: bronchoalveolar lavage; CMV: cytomegalovirus.

Seven additional cases of aspergillosis were diagnosed on additional procedures or postmortem findings. Two cases of non-CMV viral pneumonia (one due to herpes simplex virus in Group 1, one due to varicella-zoster virus in Group 2) were identified. Two cases of pulmonary alveolar proteinosis were observed in Group 2, both in patients having recently recovered normal PMN counts, whilst five cases were observed in Group 1. Two cases of hypersensitivity pneumonitis (one due to methotrexate, one due to bleomycin) were diagnosed in nonneutropenic patients.

The incidence of bacterial pneumonia was the same in Group 1 and Group 2. Most of the patients of Group 1 $(91 \%)$ were receiving antibiotics when bronchoscopy was performed. Four cases of Haemophilus influenzae pneumonia were observed in Group 2, all occurring in transplanted patients. In the 50 cases where BAL was concomitantly performed with TPC and/or PSB, the results obtained by these different procedures in terms of bacteria or Candida were always concordant, except for two possible false positives of BAL in Group 2 (table 3). The administration of antibiotics prior to endoscopy significantly decreased $(\mathrm{p}<0.02)$ the positivity of TPC and/or PSB (data not shown).

In group 1, 18 BALs were performed in patients who were in their first episode of neutropenia, and 42 in patients who were in a second or subsequent episode of neutropenia. The diagnostic yield was better in the patients in first episode $(77 \%)$, than in later episodes $(45 \%)$ $(\mathrm{p}<0.05)$. All cases of CMV and Pneumocystis carinii observed in Group 1 were in patients in second or subsequent occurrences of neutropenia. In 10 cases (6 in
Table 3. - Comparison of the microbiological yield obtained from culture of either BAL fluid or TPC/PSB sampled in 50 cases in which both BAL and TPC or PSB were concomitantly performed

\begin{tabular}{lccc}
\hline $\begin{array}{c}\text { Microbiological } \\
\text { yield }\end{array}$ & $\begin{array}{c}\text { Group 1 } \\
\mathrm{n}=20\end{array}$ & $\begin{array}{c}\text { Group 2 } \\
\mathrm{n}=30\end{array}$ & $\begin{array}{c}\text { Total } \\
\mathrm{n}=50\end{array}$ \\
\hline BAL+TPC or PSB+ & 9 & 11 & 20 \\
BAL-/TPC or PSB- & 11 & 17 & 28 \\
BAL+/TPC or PSB- & 0 & 2 & 2 \\
BAL-/TPC or PSB+ & 0 & 0 & 0 \\
\hline
\end{tabular}

BAL: bronchoalveloar lavage; TPC: telescoping plugged catheter; PSB: protected specimen brush; + : positive; - : negative.

Group 1, 4 in Group 2), two causes of pneumonia could be identified for the same episode (table 2).

\section{Complications of fibreoptic bronchoscopy}

Complications of endoscopy occurred during 2 out of $113(1.7 \%)$ procedures. One transplanted patient with CMV pneumonitis died $4 \mathrm{~h}$ after bronchoscopy from Pseudomonas aeruginosa septicaemia. Blood cultures were negative prior to the procedure. The lavage fluid culture showed $P$. aeruginosa. BAL was probably responsible for spreading bacteria from the lung in this case. One patient with Varicella zoster pneumonia developed a pneumothorax after PSB. Both these patients were in the non-neutropenic group.

Therapeutic implications of endoscopy with BAL and outcome of pneumonia

Considering that establishing a diagnosis of CMV pneumonia, aspergillosis, alveolar haemorrhage, Pneumocystis carinii pneumonia, bacterial pneumonia, or hypersensitivity pneumonia, has therapeutic implications, the overall eventual therapeutic value of all endoscopic procedures was $46 \%$ in Group 1 and $62 \%$ in Group 2 (difference nonsignificant). The therapeutic usefulness of cytological examination of BAL samples was also lower in Group $1(24 \%)$ than in Group $2(37 \%)$, but the difference was nonsignificant. The mortality rate with or from pneumonia by episode was higher in Group $1(28 \%)$ than in Group 2 (18\%), but the difference was nonsignificant.

\section{False-negative BALs}

In 10 cases (nine in Group 1, one in Group 2), a diagnosis was made subsequent to a negative BAL result (table 4). Nine of these involved fungal pneumonia: seven cases of aspergillosis diagnosed by autopsy (4), second BAL (1), transthoracic needle aspiration (1), or sputum cultures (1), one case of mucormycosis, and one case of an unspecified fungal pneumonia at autopsy. Five of these 10 patients were not receiving amphotericin $\mathrm{B}$ at the time of bronchoscopy. Additionally, one case of legionellosis (diagnosed by specific serology) was missed by the endoscopic procedure.

Among 17 of the 26 patients who died, no postmortem lung biopsy or autopsy could be performed. Only two of them had a non-contributory BAL; both were marrow transplant recipients. One died from sudden death on day 15 after transplant. The second patient died from 
Table 4. - Subsequent diagnosis in 10 episodes of pneumonia which had false-negative results on fibreoptic bronchoscopy and BAL

\begin{tabular}{lccc}
\hline & Group 1 & Group 2 & Total \\
\hline Aspergillosis & 6 & 1 & 7 \\
Mucormycosis & 1 & & 1 \\
Unidentified mycosis & 1 & & 1 \\
Legionellosis & 1 & & 1 \\
\hline Total & 9 & 1 & 10 \\
\hline
\end{tabular}

BAL: bronchoalveolar lavage

grade IV graft-versus-host disease. All the other 15 patients had a pulmonary diagnosis provided through bronchoscopy and consistent with a fatal outcome.

\section{Study of the alveolar cell populations: comparison between neutropenic and non-neutropenic patients}

The cellular pattern of BALs in terms of concentration of total cells (number of cells. $\mathrm{ml}^{-1}$ counted in an aliquot of BAL fluid), concentrations of alveolar macrophages (AMs), of PMNs, of lymphocytes, and percentage of siderophages, were compared in neutropenic and nonneutropenic patients. When two BALs had been performed for the same episode of pneumonia, only the first one was included in this study. In some cases of proteinosis, in particular, several BALs could not be accurately studied for cytological evaluation. Finally, 47 BALs in Group 1 and 50 in Group 2 entered this comparative study.

The mean concentrations of total alveolar cells, AMs, and PMNs was significantly lower in Group $1(\mathrm{p}<0.005)$ than in Group 2 (fig. 1). This difference was more significant $(\mathrm{p}<0.0005)$ when comparing BALs of Group 1A (patients with a blood PMN count $<500 \cdot \mathrm{mm}^{-3}$ ) to the BALs of Group 2. The concentration of lymphocytes was not significantly different when considering Groups 1 and 2 , but was lower in Group 1A than in Group 2 ( $\mathrm{p}<0.005)$. The duration of aplasia (more or less than 15 days, or more or less than 31 days) in Group 1 did not influence the different concentrations of cells recovered. In Group $2,53 \%$ of BALs were performed in bone marrow transplant patients. No difference in the cellular pattern was observed, when compared to non-transplanted non-neutropenic patients. Because of the small number of patients in each subgroup of underlying haematological disease and the number of different causes of pneumonia, no relationship could be found between the cellular composition of the alveoli, the haematologic disease and the cause of pneumonia.

Among the 36 BALs of Group 1A, which could be accurately studied for cytological evaluation, 25 BALs were performed in patients after aggressive chemotherapy (induction therapy for acute myeloid leukaemia or early phase after bone marrow transplantation), and 11 BALs were performed after less aggressive chemotherapy or in patients with spontaneous neutropenia (aplastic anaemia, untreated myelodysplastic syndrome, chronic lymphocytic leukaemia (CLL) on oral chemotherapy). Whilst the mean $( \pm \mathrm{SD})$ blood PMN count was not significantly different in these two subgroups of patients, the mean concentration of total alveolar cells and the mean concentration of lymphocytes were significantly

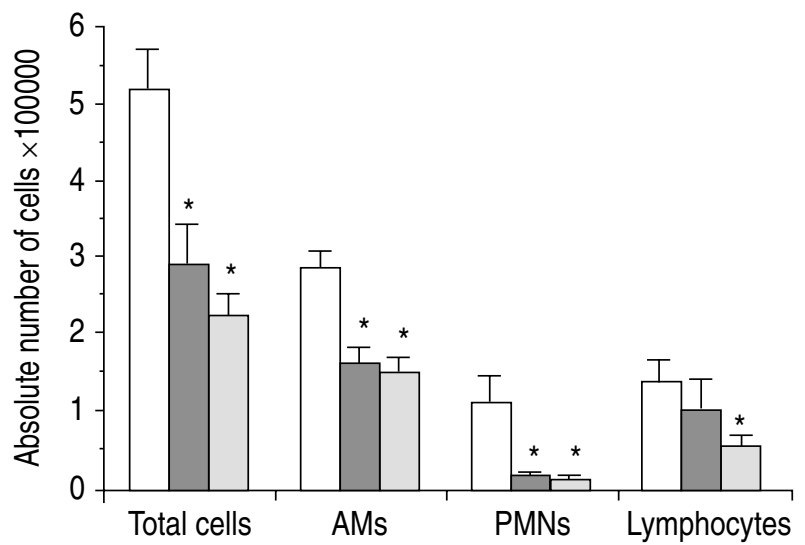

Fig. 1. - Alveolar cell populations, mean absolute number ( \pm SD), of total alveolar cells, AMs, PMNs and lymphocytes retrieved per ml of BAL fluid. All neutropenic patients (Group 1, n=47), and neutropenic patients with a blood PMN count $<500$ cells $\cdot \mathrm{mm}^{-3}$ (Group $1 \mathrm{~A}, \mathrm{n}=31$ ) were compared to non-neutropenic patients (Group 2, $n=50$ ). A p value of $<0.05$ was considered significant $(*) . \square$ : Group $2 ; \square$ : Group $1 ; \square$ : Group 1A. AMs: alveolar macrophages; PMNs: polymorphonuclear neutrophils; BAL: bronchoalveolar lavage.

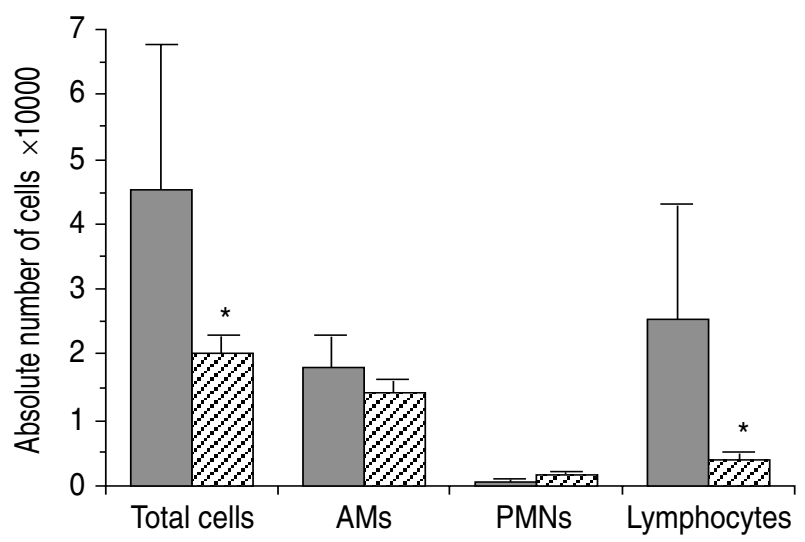

Fig. 2. - Alveolar cell populations, mean absolute number $( \pm \mathrm{SD})$, of total alveolar cells, AMs, PMNs and lymphocytes retrieved per $\mathrm{ml}$ of BAL fluid. Comparison between BAL performed in neutropenic patients of Group 1A after aggressive chemotherapy $(n=25)$, and after less aggressive chemotherapy (see text for definitions) or in patients with spontaneous neutropenia (others) $(n=11)$. A p value of $<0.05$ was considered significant (*). $\square$ : others; $\square$ : aggressive chemotherapy. For abbreviations see legend to fig. 1 .

lower ( $\mathrm{p}<0.05$ and $\mathrm{p}<0.01$, respectively) in patients after intensive induction therapy than in others (fig. 2). No significant difference was found for macrophages or PMNs.

The mean percentage of siderophages among the total population of AMs, and the number of BALs with more than $20 \%$ siderophages were surprisingly the same in Group 1 (6.2 and 7\%, respectively) and in Group 2 (5.3 and $3 \%$, respectively). The diagnosis of alveolar haemorrhage was established on cytological examination in nine cases and on the bloody nature of the alveolar fluid in one case. Among the nine patients with more than $20 \%$ siderophages, six had no other cause of pneumonia and three had aspergillosis (two diagnosed by BAL concomitantly, one diagnosed on autopsy).

\section{Discussion}

BAL was originally developed to sample the alveolar cells in diffuse interstitial diseases. In recent years, it 
has been developed mainly to investigate immunocompromised patients who are especially predisposed to pathogens involving the alveolar spaces, such as acquired immune deficiency syndrome (AIDS) patients $[1,2]$, or bone marrow or renal transplanted patients $[1,14]$. Even if several immunosuppressive factors (steroid therapy, immunoglobulin deficiency, etc.) occur in a patient, neutropenia is the most important factor predisposing to bacterial and fungal infections. We were interested to determine whether the clinical approach and/or the investigative procedures for pneumonia have to be modified in neutropenic patients [18]. The overall diagnostic yield of endoscopy with BAL in our series was $57 \%$, similar to the results of previous series of immunocompromised patients, especially those after marrow transplant [1-6, 14]. This study shows that even in neutropenic patients, bronchoscopy with BAL remains a safe and useful procedure.

The expected increased incidence of bacterial pneumonia in neutropenic patients was not found in the present series, where only 15 pneumonias were bacterial, and only 6 of these were diagnosed in neutropenic patients. Several reports emphasize the diagnostic yield of BAL with semiquantitative culture for bacterial pneumonia [19, 20]. In this retrospective series, no semiquantitative cultures were performed on BAL fluid. However, using TPC and PSB as reference procedures [17], we did observe a strong correlation between the routine culture of BAL fluid (without colony count) and the use of TPC or PSB, with only 2 out of 50 possible false-positive BAL cultures. Because we did not systematically perform TPC or PSB and we did not use BAL culture as a criterion for bacterial pneumonia, it is probable that we missed the diagnosis of some bacterial pneumonias. Another explanation could be that the legitimate and wide use of broad spectrum antibiotherapy in almost all neutropenic patients makes it difficult to diagnose bacterial pneumonia. Actually, pneumonia rarely occurs early during neutropenic periods, as indicated by the long delay (median of 32 days) between the onset of neutropenia and BAL. Because $91 \%$ of neutropenic patients were receiving antibiotics at the time of endoscopy, the influence of previous therapy on bacteriological results could not be demonstrated in this group, but the decrease in positive bacteriological cultures after antibiotics was observed for the nonneutropenic patients in Group 2.

Some causes of pneumonia were not equally distributed, such as CMV pneumonitis, which was more frequent in Group 2, reflecting the higher percentage of marrow recipients in that Group, or alveolar proteinosis, more frequent in Group 1. We have to emphasize that all the cases of alveolar proteinosis, and all except one case of aspergillosis, though diagnosed when the patient was no longer neutropenic and in Group 2, were all acquired during neutropenic periods and remain probably related to neutropenia.

The second important point is the relative high frequency of negative BAL with subsequent positive result for fungal pneumonia. This insensitivity of endoscopic procedures, including BAL, in the diagnosis of aspergillosis has been stressed previously by others $[6,21,22]$. About half of the aspergillosis in our patients was missed by bronchoscopy and BAL, particularly in Group 1 (eight fungal pneumonias misdiagnosed by BAL). More falsenegative BAL for fungi were observed in Group 1 than in Group 2. As an explanation, it can be hypothesized that: 1) fungal pneumonia is more frequent in neutropenic patients and empirical therapy with amphotericin B is more often given to neutropenic patients; 2) nonneutropenic patients with fungal pneumonia may recover better on empirical antifungal therapy; in the absence of open lung biopsy these episodes were classified as aetiologically undiagnosed; 3 ) since more patients died in Group 1 than in Group 2, the larger number of autopsies performed in Group 1 may have led to a larger number of diagnoses of aspergillosis which had been missed by BAL. Nevertheless, the means used for the diagnosis of fungal pneumonia must be improved by using other procedures than cytological examination or fungal culture, such as biochemical or antigenic assays [23, 24]. When considering Candida pneumonia, the main problem is the lack of clear diagnostic criteria on endoscopic samples. On the one hand, because of the high frequency of oropharyngeal Candida infection in neutropenic patients, there may be false-positive bronchial samples for Candida. On the other hand, we know from large series of autopsies that Candida pneumonia frequently occurs in leukaemic patients and is clearly misdiagnosed during life. SAITO et al. [6] found a clear relationship between the presence of a large number of yeasts and pseudohyphae on all fields of cytological examination and autopsy findings. In our series, we considered that two patients with positive TPC or PSB had Candida or Torulopsis pneumonia. Both also had positive stool and urine cultures and were highly colonized. Furthermore, no other pathogen than Candida was found in their lung or elsewhere, to explain pneumonia. In addition to these two patients, several had positive cultures for Candida from BAL fluid, especially in Group 1, but the lack of strong criteria led us not to consider these samples as diagnostic. It is likely that our criteria are too restrictive. Larger prospective studies, comparing cytological examination, fungal culture with colony count on BAL and TPC or PSB, autopsy findings, and possibly antigenic assays are needed to define criteria for the diagnosis of Candida pneumonia.

SAITo et al. [6] also emphasized the poor therapeutic usefulness of BAL in neutropenic patients. In our experience, endoscopy with BAL during neutropenic episodes led to changes in therapy in more than one third of the cases, which makes the procedure worthwhile in this clinical situation. This approach is, in our opinion, a good method of limiting the empirical therapies in routine practice.

The second part of this study is concerned with the compar- ison of blood and alveolar cell populations in haematological patients. Apart from experimental models, which have shown that the alveolar macrophage population seems not to be entirely dependent on production by the marrow [11-13], few clinical reports have focused on that point. In this study, we found that during neutropenic episodes, the alveolar cell population was quantitatively deficient, especially when considering AMs and PMNs. This was most significant among the more severely neutropenic patients (Group 
1A). Furthermore, in this group, the alveolar cell population was more deficient in patients on intensive induction therapy than in others. Two hypotheses may account for our observation: 1) the suppression of medullary haematopoiesis decreases the delivery of cells of myelomonocytic lineage to the lungs and reduces the alveolar cell population from extrapulmonary origin; 2) chemotherapy, especially intensive induction therapy, may directly impair the intrapulmonary turn-over of alveolar cells. Surprisingly, we did not find any relationship between the alveolar cell populations and the duration of neutropenia, but the mean and the median durations of neutropenia were especially long in this series.

Whatever the main mechanism responsible for the decrease in alveolar cells during prolonged neutropenia, this quantitative deficiency, especially in alveolar macrophages, may favour bacterial or fungal pneumonia during neutropenia, or other types of pneumonia, such as alveolar proteinosis.

In conclusion, this study shows that bronchoscopy with BAL is a safe and useful procedure in investigating pneumonia in neutropenic patients, even if the diagnostic yield and the therapeutic usefulness are slightly lower than in non-neutropenic patients. The number of false-negative results with fungal pneumonia, identified in our series, make the development of new laboratory diagnostic procedures imperative. The second important point is that prolonged neutropenia is associated with a decreased number of alveolar cells, especially alveolar macrophages and polymorphonuclear cells, leading to the concept of "lung aplasia" as a consequence or a concomitant event of marrow aplasia. The severity of "lung aplasia" could play a role in the extent or duration of infection, the efficacy of anti-infectious therapy and, finally, the clinical recovery.

Acknowledgements: The authors thank the technical assistants of the department of cytology (M.J. Pocholle and C. Aufrey), the medical staff of the Departments of Haematology, Intensive Care, Microbiology and Mycology of Hôpital Henri Mondor. They especially thank I. Cunningham for her useful comments on the manuscript.

\section{References}

1. Stover DE, Zaman MB, Hadju SI, Lange M, Gold J, Armstrong D. - Bronchoalveolar lavage in the diagnosis of diffuse pulmonary infiltrates in the immunosuppressed host. Ann Intern Med 1984; 101: 1-7.

2. Broaddus C, Dake MD, Stulbarg MS, et al. - Bronchoalveoler lavage and transbronchial lung biopsy for the diagnosis of pulmonary infections in the acquired immunodeficiency syndrome. Ann Intern Med 1985; 102: 747-752.

3. Kahn FW, Jones J, England DM. - Diagnosis of pulmonary hemorrhage in the immunocompromised host. Am Rev Respir Dis 1987; 136: 155-160.

4. De Gracia J, Curull V, Vidal R, et al. - Diagnostic value of bronchoalveolar lavage in suspected pulmonary tuberculosis. Chest 1988; 93: 329-331.

5. Xaubet A, Torres A, Marcof, De la Bellacasa JP, Faus R, Agusti-Vidal A. - Pulmonary infiltrates in immunocompromised patients: diagnostic value of telescoping plugged catheter and bronchoalveolar lavage. Chest 1989; 95: $130-135$.

6. Saito H, Anaissie EJ, Morice RC, Dekmezian R, Bodey
GP. - Bronchoalveolar lavage in the diagnosis of pulmonary infiltrates in patients with acute leukemia. Chest 1988; 94: 745-749.

7. Young LS. - Management of infections in leukemia and lymphoma. In: Rubin RH, Young LS, eds. Clinical Approach to Infection in the Compromised Host. New York, Plenum Medical Book Co., 1988; pp. 467-500.

8. Mayaud C, De Revel T, Denis M, et al. - Pneumonia in patients treated for hematological malignancy: responsible pathogens in relation to neutropenia. Am Rev Respir Dis 1989; 139 (suppl.): A427.

9. Springmeyer SC, Altman LC, Kopecky KJ, Deeg HJ, Storb R. - Alveolar macrophage kinetics and function after interruption of canine marrow function. Am Rev Respir Dis 1982; 125: 347-351.

10. Winston DJ, Territo MC, How G, Millern J, Gale RP, Golde DW. - Alveolar macrophages dysfunction in human bone marrow transplant recipients. Am J Med 1983; 73: 859-866.

11. Van Oud Albas AB, Van Furth R. - Origin, kinetics and characteristics of pulmonary macrophages in the normal steady state. J Exp Med 1979; 149: 1504-1518.

12. Sawyer RT, Strausbauch PH, Volkman A. - Resident macrophage proliferation in mice depleted of blood monocytes by strontium 89. Lab Invest 1982; 46: 165-170.

13. Tarling JD, Lin HS, Hsu S. - Self-renewal of pulmonary alveolar macrophages: evidence from radiation chimera studies. J Leuk Biol 1987; 42: 443-446.

14. Cordonnier C, Bernaudin JF, Fleury J, et al. - Diagnostic yield of bronchoalveolar lavage in pneumonitis occurring after allogeneic bone marrow transplantation. Am Rev Respir Dis 1985; 132: 1118-1123.

15. Cordonnier C, Escudier E, Nicolas JC, et al. - Evaluation of three assays on alveolar lavage fluid in the diagnosis of cytomegalovirus pneumonitis after bone marrow transplantation. J Infect Dis 1987; 155: 495-500.

16. Pham LH, Brun-Buisson C, Legrand P, et al. - Diagnosis of nosocomial pneumonia in mechanically ventilated patients. Am Rev Respir Dis 1991; 143: 1055-1061.

17. Robbins RA, Linder J, Stahl MG, et al. - Diffuse alveolar hemorrhage in autologous bone marrow transplant recipients. Am J Med 1989; 87: 511-518.

18. Wardman AG, Cooke NJ. - Pulmonary infiltrates in adult acute leukemia: empirical treatment or lung biopsy? Thorax 1984; 39: 647-650.

19. Kahn FW, Jones JM. - Diagnosing bacterial respiratory infection by bronchoalveolar lavage. J Infect Dis 1987; 155: 862-869.

20. Thorpe JE, Baughman RP, Frame PT, Wesseler TA, Staneck JL. - Bronchoalveolar lavage for diagnosing acute bacterial pneumonia. J Infect Dis 1987; 155: 855-861.

21. Kahn FW, Jones JM, England DM. - The role of bronchoalveolar lavage in the diagnosis of invasive pulmonary aspergillosis. Am J Clin Pathol 1986; 86: 518-523.

22. Yu VL, Muder RR, Poor Sattar A. - Significance of isolation of aspergillus from the respiratory tract in diagnosis of invasive pulmonary aspergillosis. Am J Med 1986; 81: 249-254.

23. Benoit G, Chauvin MF, Cordonnier C, Astier A, Bernaudin JF. - Oxalic acid level in bronchoalveolar lavage fluid from patients with invasive pulmonary aspergillosis. Am Rev Respir Dis 1985; 132: 748-751.

24. Andrews CP, Weiner MH. - Aspergillus antigen detection in bronchoalveolar lavage fluid from patients with invasive aspergillosis and aspergillomas. Am J Med 1982; 73: $372-380$. 